\title{
Upper blepharoplasty: A comparative study between wound closure strips and subcuticular closure
}

\author{
Hemin Othman Sheriff \\ Surgery Department \\ College of Medicine \\ Sulaimani University \\ Sulaimani, Iraq \\ hemin.sheriff@univsul.edu.iq
}

\author{
Ari Raheem Qader \\ Surgery Department \\ College of Medicine \\ Sulaimani University \\ Sulaimani, Iraq \\ ari.qader@univsul.edu.iq
}

Avan Hassan M. Ameen

Sulaimani Burns and Plastic Surgery Hospital

Sulaimani, Iraq

dr.avanplastic@gmail.com

\begin{abstract}
Volume 4-Special Issue: 3rd International Conference on Health \& Medical Sciences: Insight into Advanced Medical Research (ICHMS 2019)
\end{abstract}

DOI:

$10.24017 /$ science.2019

.ICHMS.27

Received:

27 May 2019

Accepted:

25 June 2019

\section{Abstract}

The objective is to compare the results of patients having their upper blepharoplasty incision closed by subcuticular suturing versus the usage of wound closure strips (Omnistrips $\left.{ }^{\circledR}\right)$. Also evaluating the time required for incision closure, any complication, and the aesthetic outcome of each technique. In this study a total of 54 upper blepharoplasty had been performed on 27 patients. Retrospective study done on 16 patients, whom incision closure done by continuous subcuticular nonabsorbable suture using 6-0 polypropylene (prolene), and another 11 patients prospectively studied for using omnistrips for their blepharoplasty incision closure. The intraoperative time which was required to finish the closure was one of the most important parameter of the study. The other parameters were the incidence of milia occurrence, presence of pain postoperatively at time of stitch and omnistrips removal, infection rate and suture acceptance. The result of this study indicated that mean time of closure was 12.36 minutes with usage of steristrips and (16.88) minutes with subcuticular suturing $(P<0.01)$. The incidence of milia was significantly reduced by using the omnistrips (P 0.004), and there was no pain encountered at time of omnistrips removal in all patients, while all other patients whom 
subcuticular suturing done for them complained of pain at the time of stitch removal. The study showed no infection associated with closure of the incision in either groups. In conclusion the closure of the incision in upper lid blepharoplasty using omnistrips is a safe, effective, faster, painless and with less complication rate than that using subcuticular suturing technique.

Keywords: blepharoplasty, scar, omnistrips, and subcuticular.

\section{INTRODUCTION AND LITERATURE REVIEW}

The procedure of the blepharoplasty has witnessed rapid development during the last few years that involved simple excision of certain tissues like skin, muscle, or even fat to an advance technique which can be optimized according to each patient condition [1]. However, risks are still considered and may involve infection, inflammation of the operated area, scarring and nonsymmetrical shaping due to unnecessary or inadequate removal of fat, skin or even muscular tissues.

In addition, the procedure could have further complications like, keratopathy, lagophthalmos, xerophthalmia, chemosis, ptosis as well as ectropion. Collectively, the commonest complications following blepharoplasty could involve scarring, lagophthalmos and ptosis of the eyelid [2].

Although scaring is one of the frequent issues encountered following operation, literature data lacks details about the materials and methods applied during the suturing of the incision and this step is essentially depends on the general techniques applied by the surgeon setting and practice $[3,4]$. The healing pace of the skin in the eyelid is faster than any other part of the body though, it does require precise closure of the wound to prevent such complications as scaring and asymmetries and the scar area could appear raised and pigmented especially in those patients who are keloid formers [5].

The procedure blepharoplasty in the upper eyelid involve removal of the flabbiness found in skin, fat or muscles of the skinfold [6] and the incision area is usually sealed via finest suture for a week [7]. Other methods for stitching the incision have been also considered over the last few decades like cyanoacrylates an adhesive made of polymers applied to the incised skin, yet records have shown cytotoxicity of the subcutaneous tissues when the product is applied $[8,9]$.

Another method of closing the blepharoplasty wound involve the application of wound adhesive strips. They consist of fine wound adhesive strips that aid in attaching the margins of the incised skin and has the advantage over staples and sutures of no traces of suture will appears on the healing area and can be applied according to patient preference and in such instances where no staples or sutures are available. Also, this method is relatively easy to use and has less scaring formation as well as it helps reducing the inflammation process following blepharoplasty procedure [10-12].

The aim of this study is to compare the results of patients having their upper blepharoplasty incision closed by subcuticular suturing versus the usage of wound closure strips (Omnistrips®), and evaluating closure time, any complication, and also the aesthetic outcome. 


\section{METHODS AND MATERIALS}

In this study a total of 54 upper blepharoplasty had been performed on 27 patients. Of those, 16 cases retrospectively followed up, their incisions closed with the continuous subcuticular suturing and another prospective study on 11 patients using omnistrips for skin closure.

The procedure of upper blepharoplasty done in a period from January 2017 till October 2018 in Sulaimany- Iraq. We included female patients aged from 35-65 years of age (average age is 48 years), exclusion criteria involved: any revision blepharoplasties, patients with connective tissue disease, diabetes, history of using anticoagulants, or those who didn't attend the respective postoperative follow-ups.

Assessments were done by appraising: appearance of the wound scar, discomfort from removing the sutures or the omnistrips, time needed for each technique of closure, the cost of utilized materials, erythema of the incision site, suture marks, wound infection, milia, standing cone deformity (SCD) and wound dehiscence. Follow up was done in a period between (6 months - 22 months).

After obtaining an informed consent from the patients for the operation, the excess upper lid skin marked with a waterproof skin marker pen in a curvilinear shape (fig.1 A). Then Lidocaine with epinephrine $(1: 100000)$ mixed with Bupivacaine with adrenaline (1:40000) used as local anesthesia and injected by $27 \mathrm{G}$ needle. After waiting 7-10 minutes in order for the local anesthesia and adrenaline to work, a fine tip radiofrequency electrocautery used for excising the excess skin and orbicularis muscle on bloc. Removing fat from the compartments was decided by the senior author after evaluating the lid by inspection and by slight orbital pressure to see if any bulging of fat occurs (fig. $1 \mathrm{~B}$ ).

Dermal layer closure done by interrupted stiches (7-8 stitches) using 6.0 fast absorbable polygalacin (Vicryl Rapide $\left.{ }^{\circledR}\right) 11 \mathrm{~mm}$ reverse cutting suture in both groups of the study ( fig.1 $\mathrm{C}$ ), and the skin closed by 6-0 prolene suture in continuous subcuticular fashion in the first group (fig. $2 \mathrm{~B}$ ). The suture was removed after 7 days from surgery and follow-up done in a period between (6months-28 months). Fig. $2 \mathrm{~A}$ preoperative photo, fig. $2 \mathrm{C}$ postoperative photo after 1 year.

In the second group, the suturing of the dermal layer was in such a way that stretching the margins of the incision in a vertical direction will not separate it from each other, and the edges are everted ( fig. $1 \mathrm{C}$ ). After finishing the dermal layer closure, the wound is prepped with benzoin tincture which has stickiness propriety and make omnistrips adherence to the wound even better and stronger. Three layer of omnistrips were applied to the wound along its length horizontally ( fig. $1 \mathrm{D}$ ) and patient sent home and advised coming back in the third postoperative day for changing the steristrips( fig.1 E ). Another three layers of omnistrips was applied and the patient was instructed to remove the steristrips after another 2 days and take a shower. Photographs taken for this group in 3 months and 6 months for follow up ( fig.1 F, G ).

Rating of the scar appearance was performed by 6 plastic surgeons blinded to the method of closure who analyzed standardized patient photographs taken in a period ranged(3months -12 months) postoperatively and answered a Hollander scale questionnaire for wound cosmetic appearance ( table 1 ). 

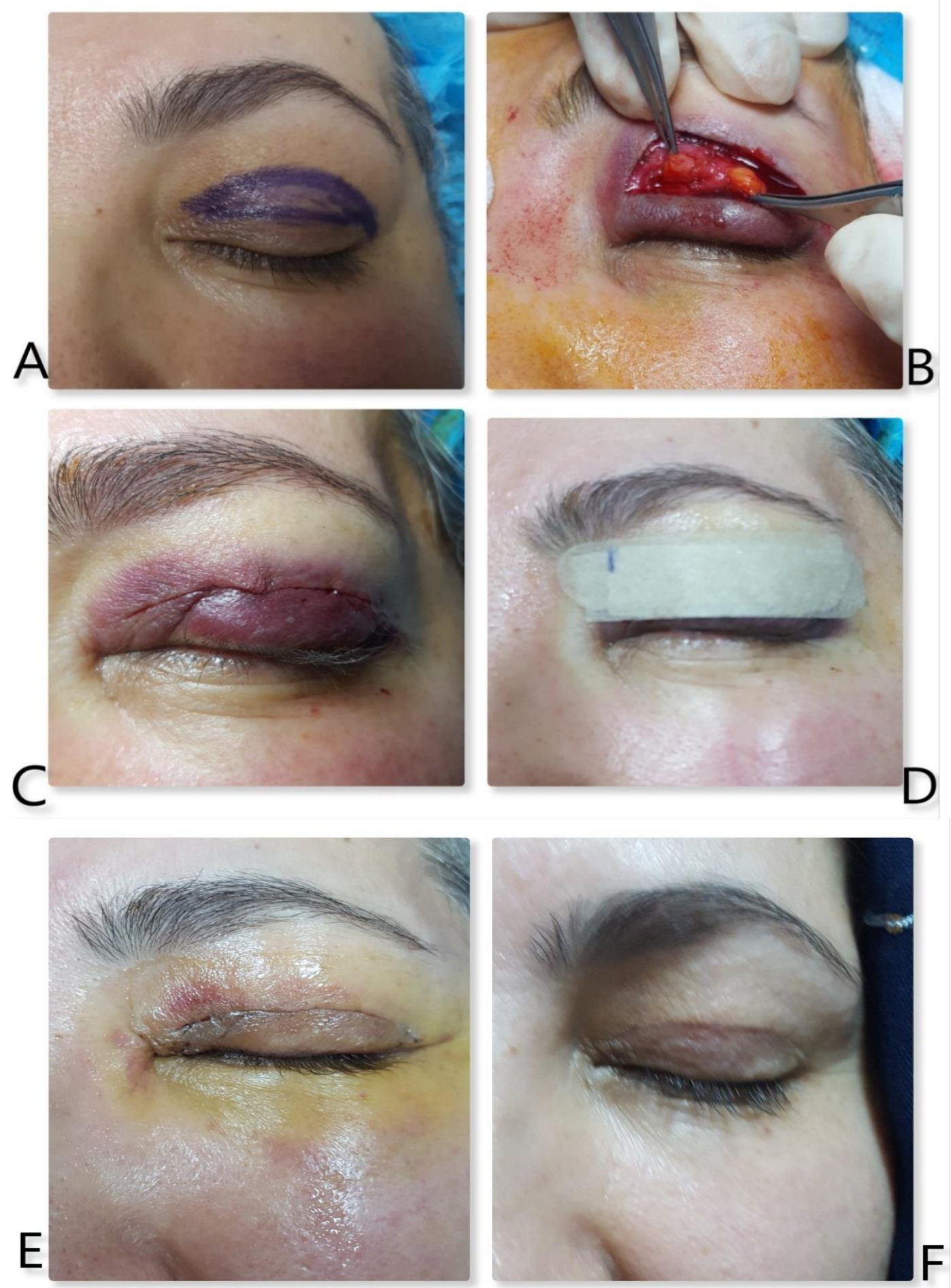

Fig. 1 (continued) 


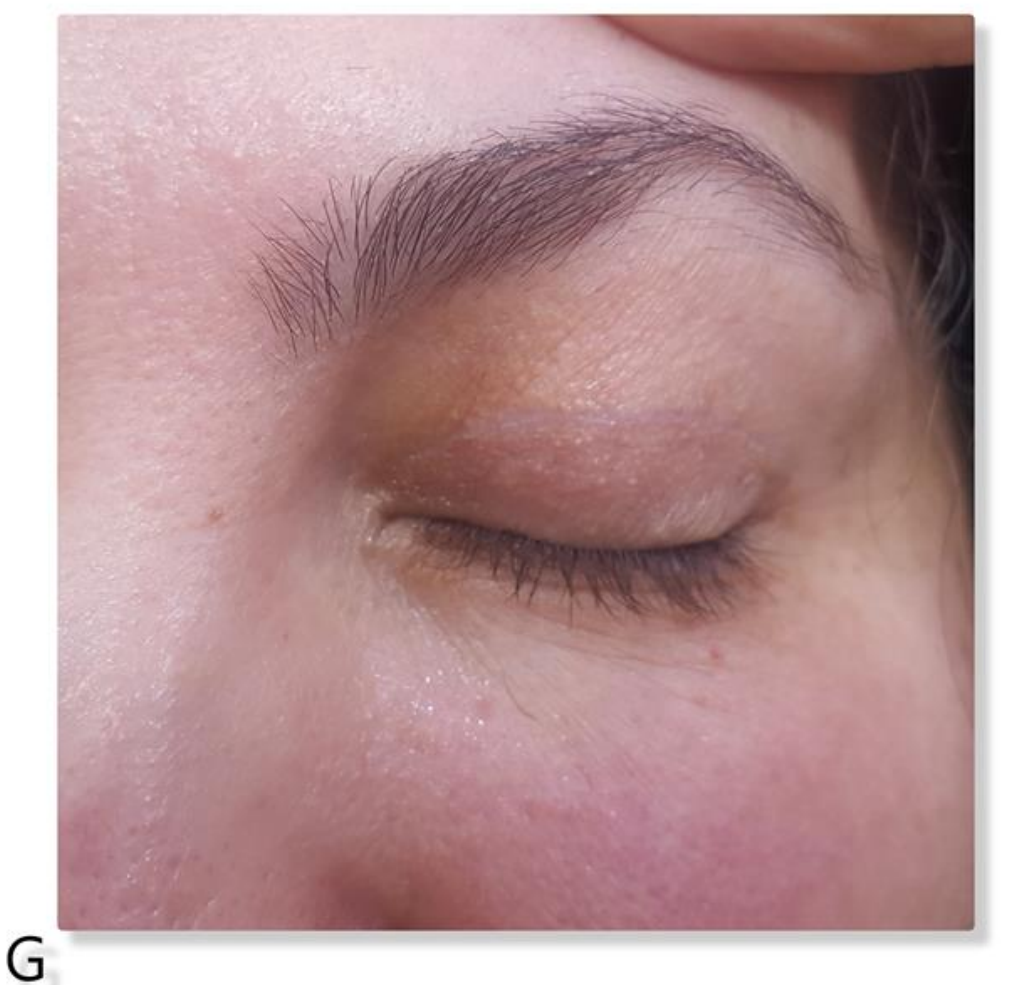

Fig .1 a 48 years old lady underwent upper blepharoplasty (wound closure strips technique) A) Preoperative marking. B) Excision of fat from the orbital compartments. C) Dermal layer closure by 6.0 vicryl rapide. D) Application of 3 layers of omnistrips horizontally .E) 3rd Postoperative day photo. F) Postoperative photo after 3 months. G) Postoperative photo after 6 months. 

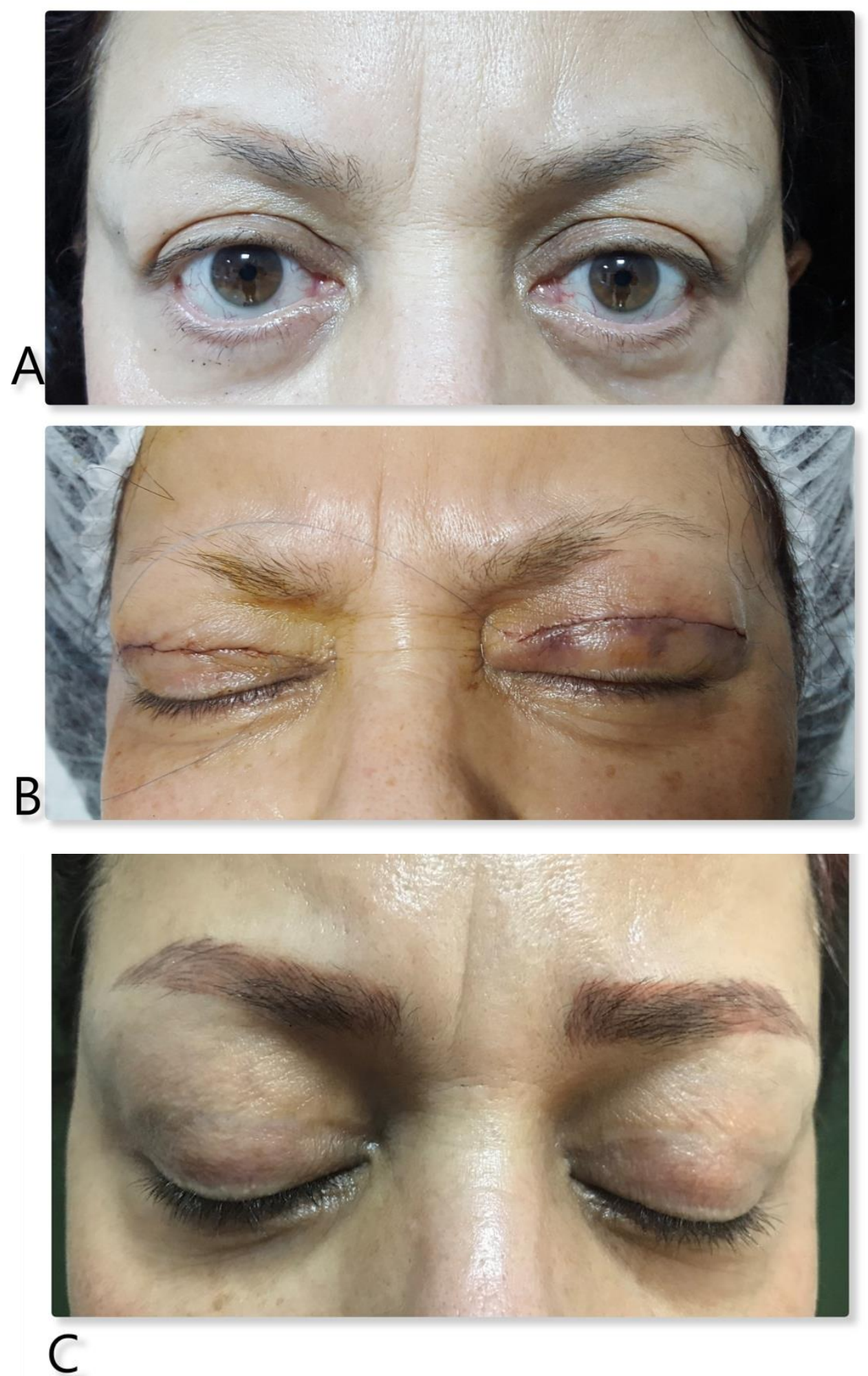

Fig.2 A 60 years old lady underwent upper blepharoplasty (subcuticular technique). A) Preoperative photo. B) Subcuticular suturing by 6-0 prolene. C) Postoperative photo after one year. 
Table.1 - Hollander scale for cosmetic appearance

\begin{tabular}{lcc}
\hline Clinical appearance & Yes & No \\
\hline Step off Margins ( Edges not in the same plane) & 0 & 1 \\
\hline Contour Irregularities ( wrinkled skin near the wound) & 0 & 1 \\
\hline Margin Separation ( gap between the sides) & 0 & 1 \\
\hline Edge inversion ( wound not properly everted) & 0 & 1 \\
\hline Excessive distortion (from swelling, edema, or infection) & 0 & 1 \\
\hline Overall appearance & Poor & Good \\
\cline { 2 - 2 }
\end{tabular}

Total cosmetic score ( 0 to 6 )

\section{RESULTS}

\subsection{Comparison between subcuticular suturing and of usage of omnistrips regarding the time} for skin closure.

Table 2 shows that lowest mean of time (minutes) was demanded for cloure of blepharoplasty incision by using of omnistrips (new method) $(12.36 \pm 1.12 \mathrm{~min}$ ) as compared with subcuticular suturing (old method) $(16.88 \pm 1.67 \mathrm{~min})$ with highly significant difference between the two method $(\mathrm{P}<0.01)$.

Table 2: Comparison between subcuticular suturing and of usage of omnistrips regarding the time of surgery.

\begin{tabular}{ccccc}
\hline $\begin{array}{c}\text { The time of surgery } \\
(\text { min/eye) }\end{array}$ & $\begin{array}{c}\text { subcuticular } \\
\text { suturing }\end{array}$ & $\begin{array}{c}\text { usage of } \\
\text { omnistrips }\end{array}$ & T. Test & P. value \\
\cline { 1 - 3 } No. & 16 & 11 & 7.81 & $0.0001^{*}$ \\
\cline { 1 - 3 } Mean & 16.88 & 12.36 & \\
\hline SD. & 1.67 & 1.12 & \\
\hline
\end{tabular}

$* \mathrm{P}$. value $<0.01$ : highly significant

3.2. Difference between subcuticular suturing and of usage of omnistrips regarding the formation of milia after surgery.

The present study found that formation of milia after blepharoplasty incision was significantly reduced $(\mathrm{P}<0.01)$ when applying incision by using of omnistrips with rate of $27.27 \%$ as compared with $50 \%$ in subcuticular suturing method, (Table 3 ). 
Table 3: Difference between subcuticular suturing and of usage of omnistrips regarding the formation of milia after surgery

\begin{tabular}{ccccc}
\hline \multirow{2}{*}{ Formation of milia } & \multicolumn{2}{c}{ subcuticular suturing } & \multicolumn{2}{c}{ usage of omnistrips } \\
\cline { 2 - 5 } & No. & $\%$ & No. & $\%$ \\
\hline Present & 8 & 50 & 3 & 27.27 \\
\hline Absent & 8 & 50 & 11 & 72.73 \\
\hline Total & 16 & 100 & highly significant & \\
\hline & $* \mathbf{X}^{\mathbf{2}} \mathbf{1 0 . 8 9}$ & & P: $\mathbf{0 . 0 0 4}$ &
\end{tabular}

\subsection{Difference between subcuticular suturing and of usage of omnistrips concerning the} formation of standing cone deformity (SCD) after surgery.

The present study found that formation of SCD after blepharoplasty incision was reduced when closing the incision by using of subcuticular method with rate of $18.75 \%$ as compared with $27.27 \%$ in omnistrips method. Although the result was non-significant, (Table 4).

Table 4: Difference between subcuticular suturing and of usage of omnistrips concerning the formation of standing cone deformity (SCD) after surgery

\begin{tabular}{ccccc}
\hline \multirow{2}{*}{ Formation of SCD } & \multicolumn{2}{c}{ subcuticular suturing } & \multicolumn{2}{c}{ usage of omnistrips } \\
\cline { 2 - 5 } & No. & $\%$ & No. & $\%$ \\
\hline Present & 3 & 18.75 & 3 & 27.27 \\
\hline Absent & 13 & 81.25 & 11 & 100 \\
\hline Total & 16 & 100 & non-significant \\
\hline
\end{tabular}

$*$ P. value $>0.05$ : non-significant

\subsection{Difference between subcuticular suturing and of usage of omnistrips concerning the presence of pain at time of stitch or omnistrips removal.}

The present study found that all patients of blepharoplasty did not suffer from pain at time of omnistrips removal while all patients with the subcuticular suturing method suffered from pain with the stich removal (Table 5).

Table 5: Difference between subcuticular suturing and of usage of omnistrips concerning the presence of pain at stich or omnistrips removal

\begin{tabular}{ccccc}
\hline \multirow{2}{*}{ Pain } & \multicolumn{2}{c}{ subcuticular suturing } & \multicolumn{2}{c}{ usage of omnistrips } \\
\cline { 2 - 5 } & No. & $\%$ & No. & $\%$ \\
\hline Present & 16 & 100 & 0 & 0 \\
\hline Absent & 0 & 0 & 11 & 100 \\
\hline Total & 16 & 100 & highly significant & \\
\hline & $\mathbf{X}^{\mathbf{2}} \mathbf{2 7 . 8}$ & & $*$ P: $\mathbf{0 . 0 0 0 0 1}$ &
\end{tabular}




\subsection{Presence and absence of dehiscence, suture marks, erythema and infections after surgery between the two methods.}

Table 6, shows that both of the methods of blepharoplasty incision closure technique were characterized with no occurrence of dehiscence, suture marks, infections and erythema.

Table 6: Presence or absence of dehiscence, suture marks, erythema and infections after surgery between the two methods.

\begin{tabular}{cccccc}
\hline \multirow{2}{*}{} & & \multicolumn{2}{c}{ subcuticular suturing (n:16) } & \multicolumn{2}{c}{ usage of omnistrips (n:11) } \\
\cline { 2 - 6 } & & No. & $\%$ & No. & $\%$ \\
\hline \multirow{2}{*}{ Dehiscence } & Present & 0 & 0 & 0 & 0 \\
\cline { 2 - 6 } & Absent & 16 & 100 & 11 & 100 \\
\hline \multirow{2}{*}{$\begin{array}{c}\text { Suture } \\
\text { marks }\end{array}$} & Present & 0 & 0 & 0 & 0 \\
\cline { 2 - 6 } Infections & Absent & 16 & 100 & 11 & 100 \\
\cline { 2 - 6 } Erythema & Present & 0 & 0 & 0 & 0 \\
\cline { 2 - 6 } & Absent & 16 & 0 & 11 & 100 \\
\cline { 2 - 6 } & Present & 0 & 100 & 11 & 100 \\
\hline
\end{tabular}

\subsection{Satisfaction of the consultant doctors about the surgical science.}

The difference between the two methods in terms of the satisfaction of the consultant doctors about the surgical science after a period of the incision was non-significant, (Table 7).

Table 7: Satisfaction of the consultant doctors about the surgical science

\begin{tabular}{cccc}
\hline $\begin{array}{c}\text { The time of surgery } \\
(\text { min/eye) }\end{array}$ & $\begin{array}{c}\text { subcuticular } \\
\text { suturing }\end{array}$ & usage of omnistrips & P. value \\
\hline No. & 16 & 11 & \multirow{2}{*}{0.46} \\
\hline Mean & 5.36 & 5.12 & \\
\hline SD. & 0.26 & 0.21 & 1.66 \\
\hline Percentage of acceptance & $86.9 \%$ & $82.89 \%$ & \\
\hline
\end{tabular}

\section{DISCUSSION}

As there are many methods for blepharoplasty incision closure and many different suture materials [2], in our study we are trying a new method of wound closure strips with deep dermal absorbable sutures and discuss about its advantages and disadvantages.

One similar study done earlier showed that that the wound closure strips (Steri-Strip ${ }^{\mathrm{TM}}$ ) brand of co-aptive method (film) was an appropriate option to sutures without rate of wound contamination, dehiscence or skin irritation [13]. Kerrigan and Homa found that Steri-Strip allows quicker closure of wounds than suture [14], and Lazar et al announced that Steri-Strip diminishes erythema [13]. 
There are numerous written works which are likewise discussing suture less closure of blepharoplasty utilizing cyanoacrylate versus to regular suturing in upper blepharoplasty [8, 15, 16]. M.M. Suriano et al who published their article in 2011[16], Luis Fernando Perin et al who published in 2009[8], and Ahn HB et al who also published in 2011[17], all of these had researches on closing upper blepharoplasty incision in human and rabbits by using cyanoacrylate adhesives. But surprisingly there is paucity of literatures dealing with incisional closure in blepharoplasty using wound closure strips. However, we found one article from Farhangi Monika B.S et al which reported the use of Steri-Strip for upper blepharoplasty incision after suturing by conventional method and it's benefit as cost effective and better wound healing properties [18].

In our study, we observed a significant decrease in the time required for closure by using the omnistrips (mean time 12.36 +/- $1.12 \mathrm{~min}$ ), as compared with the time needed for closure using subcuticular method (mean time $16.88+/-1.67 \mathrm{~min}$ ) with nearly the same aesthetic outcomes. this finding matches the majority of studies review prior to our study involving the use of cyanoacrylates[8, 15-17], also van de Gevel DF et al found that Steri-strips was a fast method for closing sternotomy wounds in patients having coronary bypass surgery compared to intracuticular sutures [19], as well as by the study of by IM Anuar Ramdhan et al study showed to be a faster way for wound closure than sutures [20].

Regarding the pain, all omnistrips technique group $(\mathrm{N}=11)$ noticed to be a pain free when removing the tape (because it eliminated postoperative stich removal), while all patients with subcuticular sutures $(\mathrm{N}=16)$ suffered from pain at time of stich removal. Same results found in the articles comparing cyanoacrylates with suturing techniques $[8,16]$.

Statistical analysis showed a significant decrease in milia formation in omnistrips method ( $27.27 \%$ only present) because no needle was introduced through the epidermis compared to subcuticular suturing method (present 50\%), while there was a non-significant increase in the rate of standing cone deformity in omnistrips method patients. We didn't find similar comparison in the articles we use as a reference to this study.

There was no any distinction between the two methods regarding the presence of infection, dehiscence, or suture marks. Results simulate the other articles that are comparing between suturing and cyanoacrylates $[8,17]$.

There were cases of minor wound dehiscence in a study done by Luis Fernando Perin et al due to poor wound approximation and eversion because of using only forceps or traction sutures to approximate the wound edges[8].Other study by IM Anuar Ramdhan et al learn about comparison between wound closure strips and suture for closing incisions after long bone fractures stabilization demonstrated that inconvenience rate was not measurably noteworthy. Besides, the scar delivered by Steristrip was not wider than that created by sutures as of the twelfth week follow-up visit [20].

An examination done by Arjun S. Joshi et al in 2007[2] looking at the utilization of various suture materials and methods for upper blepharoplasty conclusion, they found that utilizing absorbable plain gut sutures was related with persevering erythema because of deferred and variable breakdown of the plain gut suture. To conquer this issue we utilized Vicryl Rapide for the dermal stiches and luckily no erythema experienced in either gatherings.

Another advantage in our study is that we can conquer the cutting of the suture while removing it so that a piece of it may remain inside the scar and that patient may sometimes complain from it sooner or later as a somewhat blue or other shading (as per the shade of the prolene suture) line at the site of the scar.

The distinction in the expense between the two strategies for closure is of debate, in spite of the fact that omnistrips might be similarly or even in some cases more exorbitant than prolene sutures(according to the expense of suture material industries). But wound closure strips technique would diminish the cost on the grounds that specific instruments and help would not be required because of the simplicity and instantaneousness of use. And also by reducing the surgery time with the utilization of omnistrips, the medical procedure room expenses are indirectly decreased [20]. Same outcome noticed with the cyanoacrylate strategy for closure by Suriano et al [16]. 
With respect to the observers's fulfillment according to Hollander scale, there was no significant increment in satisfaction for the subcuticular strategy bunch over the wound closure strips gatherings. This is maybe because of the long follow-up time for the results of subcuticular closures in contrast to those of omnistrips. We found an investigation by Quinn J, Wells $\mathrm{G}$ et al which demonstrate no distinction is observed in the asthetic appearance of skin wounds created by trauma treated with cyanoacrylate in contrast to sutures following one year from wound fix [21].

Impediment of our examination can be expected due to the follow-up time discrepancy between the two gatherings, prompting diverse course of events for each scar to watch accordingly.

The other constraint of the study was because of the diverse dermatological attributes for every patient, it would have been more properly if both techniques were administered for the exact same patient (one strategy for each eye), so as to make examinations under the equivalent dermatological conditions for the two strategies.

So in regards to the confinements referenced above, later on we can do a planned report for contrasting both of the techniques for a similar patient (one method for each eye) and increment the sample number with greater pledge to the follow up time for every patient.

\section{CONCLUSION}

Wound strip closure of upper blepharoplasty incision is a safe, easy, cost-effective method with nearly same aesthetic results compared to subcuticular closure technique with less time and pain, and reduced rate of milia formation postoperatively.

\section{REFERENCE}

[1] S. R. Thaller, "Grabb and Smith's Plastic Surgery, Seventh Edition," Plastic and Reconstructive Surgery, vol. 133, pp. 1311-1312, 2014.

[2] A. S. Joshi, et al., "Does suture material and technique really matter? Lessons learned from 800 consecutive blepharoplasties," Laryngoscope, vol. 117, pp. 981-4, Jun 2007.

[3] S. Fagien, "Advanced rejuvenative upper blepharoplasty: enhancing aesthetics of the upper periorbita," Plast Reconstr Surg, vol. 110, pp. 278-91, 2002.

[4] R. J. Rohrich, et al., "Current concepts in aesthetic upper blepharoplasty," Plast Reconstr Surg, vol. 113, pp. 32e-42e, 2004.

[5] J. Oestreicher and S. Mehta, "Complications of blepharoplasty: prevention and management," Plastic surgery international, vol. 2012, pp. 252368-252368, 2012.

[6] J. B. Hellman, et al., "Safety and Efficacy of Resident-Performed Functional Upper Eyelid Blepharoplasty," Ophthalmic Plast Reconstr Surg, vol. 24, p. 0000000000001395, 2019.

[7] S. M. Pool, et al., "Improved upper blepharoplasty outcome using an internal intradermal suture technique: a prospective randomized study," Dermatol Surg, vol. 41, pp. 246-9, Feb 2015.

[8] L. F. Perin, et al., "Sutureless closure of the upper eyelids in blepharoplasty: use of octyl-2-cyanoacrylate," Aesthet Surg J, vol. 29, pp. 87-92, Mar-Apr 2009.

[9] D. M. Toriumi, et al., "Histotoxicity of cyanoacrylate tissue adhesives. A comparative study," Arch Otolaryngol Head Neck Surg, vol. 116, pp. 546-50, 1990.

[10] P. J Murray, CLOSURE OF SKIN WOUNDS WITH ADHESIVE TAPE. PRELIMINARY REPORT BASED ON USE OF TAPE IN 100 SURGICAL CASES vol. 2, 1963.

[11] R. Babu K, et al., POPULARIZING POOR MAN'S STERI-STRIP - WASH PROOF BAND-AID vol. 3 , 2014.

[12] H. P. Hirshman, et al., "Penetration of Staphylococcus aureus into sutured wounds," J Orthop Res, vol. 2, pp. 269-71, 1984.

[13] H. L. Lazar, et al., "Adhesive strips versus subcuticular suture for mediansternotomy wound closure," $J$ Card Surg, vol. 26, pp. 344-7, 2011.

[14] C. L. Kerrigan and K. Homa, "Evaluation of a new wound closure device for linear surgical incisions: $3 \mathrm{M}$ Steri-Strip S Surgical Skin Closure versus subcuticular closure," Plast Reconstr Surg, vol. 125, pp. 186-94, 2010.

[15] D. Greene, et al., "Efficacy of octyl-2-cyanoacrylate tissue glue in blepharoplasty. A prospective controlled study of wound-healing characteristics," Arch Facial Plast Surg, vol. 1, pp. 292-6, Oct-Dec 1999.

[16] M. M. Suriano, et al., "Blepharoplasty: to suture or to use cyanoacrylate?," Archivos de la Sociedad Española de Oftalmología (English Edition), vol. 86, pp. 81-84, 2011/01/01/ 2011. 
[17] H. B. Ahn, et al., "A comparison of 2-octyl cyanoacrylate adhesives versus conventional suture materials for eyelid wound closure in rabbits," Korean J Ophthalmol, vol. 25, pp. 121-7, Apr 2011.

[18] M. B. S. A. Farhangi, Usiwoma E. M.D.; Cockerham, Kimberly P. M.D., F.A.C.S. ( 2017, Issue 4). Novel Approach to Skin Closure Following Upper Eyelid Blepharoplasty.

[19] D. F. van de Gevel, et al., "Is the use of Steri-StripTM S for wound closure after coronary artery bypass grafting better than intracuticular suture?," Interact Cardiovasc Thorac Surg, vol. 10, pp. 561-4, 2010.

[20] I. Anuar Ramdhan, et al., "Comparative study between coaptive film versus suture for wound closure after long bone fracture fixation," Malaysian orthopaedic journal, vol. 7, pp. 52-55, 2013.

[21] J. Quinn, et al., "Tissue adhesive versus suture wound repair at 1 year: randomized clinical trial correlating early, 3-month, and 1-year cosmetic outcome," Ann Emerg Med, vol. 32, pp. 645-9, 1998. 